\title{
Selection criteria for building performance simulation tools : contrasting architects' and engineers' needs
}

\author{
Attia, S.G.; Hensen, J.L.M.; Beltran, L.; De Herde, A.
}

Published in:

Journal of Building Performance Simulation

DOI:

10.1080/19401493.2010.549573

Published: 01/01/2012

Document Version

Accepted manuscript including changes made at the peer-review stage

Please check the document version of this publication:

- A submitted manuscript is the author's version of the article upon submission and before peer-review. There can be important differences between the submitted version and the official published version of record. People interested in the research are advised to contact the author for the final version of the publication, or visit the DOI to the publisher's website.

- The final author version and the galley proof are versions of the publication after peer review.

- The final published version features the final layout of the paper including the volume, issue and page numbers.

Citation for published version (APA):

Attia, S. G., Hensen, J. L. M., Beltran, L., \& De Herde, A. (2012). Selection criteria for building performance simulation tools : contrasting architects' and engineers' needs. Journal of Building Performance Simulation, 5(3), 155-169. DOI: $10.1080 / 19401493.2010 .549573$

\section{General rights}

Copyright and moral rights for the publications made accessible in the public portal are retained by the authors and/or other copyright owners and it is a condition of accessing publications that users recognise and abide by the legal requirements associated with these rights.

- Users may download and print one copy of any publication from the public portal for the purpose of private study or research.

- You may not further distribute the material or use it for any profit-making activity or commercial gain

- You may freely distribute the URL identifying the publication in the public portal ? 


\title{
Selection Criteria for Building Performance Simulation Tools: Contrasting Architects and Engineers Needs
}

\author{
Shady Attia ${ }^{\mathrm{a}^{*}}$, Jan LM Hensen ${ }^{\mathrm{b}}$, Liliana Beltrán ${ }^{\mathrm{c}}$ and André De Herde ${ }^{\mathrm{a}}$ \\ ${ }^{a}$ Architecture et climat, Université catholique de Louvain, Louvain La Neuve, Belgium \\ ${ }^{\boldsymbol{b}}$ Building Physics and Systems, Eindhoven University of Technology, The Netherlands \\ ${ }^{c}$ Department of Architecture, Texas A\&M University, USA \\ Corresponding author: shady.attia@uclouvain.be
}

\begin{abstract}
This paper summarizes a study undertaken to reveal potential challenges and opportunities for using building performance simulation (BPS) tools. The paper reviews current trends in building simulation and outlines major criteria for BPS tools selection and evaluation based on analyzing user's needs for tools capabilities and requirement specifications. The research is carried out by means of a literature review and two online surveys. The findings are based on an inter-group comparison between architects and engineers'. The aim is to rank BPS tools selection criteria and compare ten state-of-thearts BPS tools in the USA market. Five criteria are composed to stack up against theories and practices of BPS. Based on the experience gained during the survey, suggested criteria are critically reviewed and tested. The final results indicate a wide gap between architects and engineers priorities and tools ranking. This gap is discussed and suggestions for improvement of current tools are presented.
\end{abstract}

Keywords: building performance simulation, selection criteria, comparison, architect, engineer, survey

\section{Introduction}

The use of Building Performance Simulation (BPS) tools by design professionals became a fundamental way to support design decisions for energy efficient buildings. Given the breadth of choices of BPS tools, architects and engineers are challenged with the selection process of these tools in everyday building design. In 2010, the number of tools listed on the U.S. Department of Energy (DOE) Building Energy Software Tools Directory (BESTD) website reached more than 389 (DOE 2010, Crawley 1997). Between 1997 and 2010 the number of tools has almost quadrupled (Figure 01). The growing number of tools resulted into a growing landscape that is considered in itself as a barrier. Users visiting the BESTD website are faced with an overwhelming array of choices including the tool's targeted audience, design phase, project type, interoperability, accuracy, etc.

Meanwhile, there is no independent evaluation and classification of tool usability and functionality in relation to the needs of different user types (Clarke, 2009). Tools developers 
rarely state the tool's capabilities and limitations (Reinhart, 2006). The potential user is faced with difficulty of choosing a suitable tool among the growing BPS tools pool. Therefore, we need to clearly identify the needs of different users versus tool capabilities and limitations in order to facilitate the selection process.

The paper describes a study taken to address this problem. The objective of this study was two-fold. (1) The first goal is to identify user (architects and engineers) requirements and selection criteria for BPS tools. This is done through a literature review identifying the major selection criteria within the architectural and engineering fields. The second goal is to test those criteria by ranking ten BPS tools and conducting an inter-group comparison between architects and engineers through two online surveys.

This paper is organized into six sections. The first section identifies the research problem within the BPS community. The second section screens the selection criteria and requirement specifications of tools regarding their usability and functionality. These criteria form the basis for the two online surveys discussed in the third section. The analysis of the results and the survey findings are presented in chapter four. The final two sections are discussing the survey findings and providing feedback to tool developers and the architecture and engineering education community.

\section{Tools Selection Criteria}

The simulation community does not have clear criteria to classify and evaluate the facilities offered by tools (Crawley, Hand et al. 2008). There are not yet uniform definitions of tool requirements and specifications based on formal consultations with users, practitioners and tool developers (Clarke, 2009). There is no common language to describe what the tools could do (Crawley, Hand et al. 2005). In literature for example, there are many nuances to describe the 
tool capabilities including words such as criteria, requirements, functionality, specifications, features, factors etc. Also, there is no clear methodology to compare BPS tools. In order to provide the necessary conditions for an evolutionary cycle of tool development; a critical review of the status quo and in-depth reflections on the tools must be achieved (Lam, Wong et al. 1999). The following review forms an entrée into the literature.

\subsection{Previous studies}

A number of studies and surveys have been carried out in the past that were concerned with the criteria and requirements of BPS tools. Those studies and surveys can be classified under two mainstreams.

The first mainstream aimed to identify criteria and requirements of BPS tools. For example, the study of Crawley and Lawrie (1997) where developers and users were invited to provide input on next-generation building energy simulation tool requirements. Two workshops focused mainly on the applications, capabilities, methods and structures for the development of the calculation engine of EnergyPlus. User interface issues were not discussed. Later, the work of Hong et al. (2000) presented an overview of development of BPS. Aiming to set up a criteria to select a BPS tool, the authors suggested four selection criteria including usability, computing capability, data exchange capability and database support. In 2002, Augenbroe presented an overview of the trends in building simulation. The author did not address tool evaluation criteria in particular. However, in his work he highlighted emerging trends regarding interoperability, knowledge base integration, and adaptability for different design phases and design teams in addition functional and validation criteria (Augenbroe, 2002). Also Pilgrim et al. in (2003) conducted a study aiming to identify barriers to the use of BPS tools. The study focused mainly on evaluating the presentation of post-processing output results. The most recent study is 
developed by Weytjens et al. (2010) and focus mainly on identifying tools criteria from the point of view of architects.

The second mainstream found in literature is studies that aim to rank and compare BPS tools, including the studies of Lam et al. (2004), Crawley et al. (2008), Riether et al. (2008), Attia et al. (2009) and Weytjens et al. (2010). The most significant among them is the study of Lam et al. in 2004 and Crawley et al. in 2005. The study of Lam developed a classification schema for comparing five tools based on four major criteria. These criteria are usability, functionality, reliability and prevalence. The author provided no information on the methodology and sources used to compile the criteria. The other study of Crawley compared the capabilities of twenty major BPS tool. But the comparison criteria were based on vendor-supplied information with 18 categories including: results reporting, validation, user interface and links to other programs (Crawley, Hand et al. 2008).

Summing up, previous studies were capable of identifying general trends and needs in the BPS community. However, most those studies focused on generating temporary feedback and wish lists by ranking and comparing specific BPS tools. The time validity of these studies is often short and often represents a mono-disciplinary evaluation approach. A standard and methodological framework for comprehensive tool evaluation is missing. There is not yet a uniform and clear methodology or outline to assess and define tool specifications and criteria for developers, practitioners and tool users.

\subsection{Tools selection criteria}

Aiming to address this problem, this paper suggests a set of comprehensive selection criteria for BPS tools. By screening the existing literature it was found that the simulation community at large is discussing at least five major topics. Figure 02 classifies those five criteria as follows: 
- (1) Usability and Information Management (UIM) of interface

- (2) Integration of Intelligent design Knowledge-Base (IIKB)

- (3) Accuracy of tools and Ability to simulate Detailed and Complex building Components (AADCC)

- (4) Interoperability of Building Modelling (IBM)

- (5) Integration with Building Design Process (IBDP)

The aim of presenting the five selection criteria is not to conduct an exhaustive analysis.

Instead, it is to tease out broad yet critical underlying premises to see if common ones exist. The five criteria are presented in the following paragraphs in detail.

\subsubsection{Usability and Information Management (UIM) of the interface}

The Usability and Information Management of the interface is a fundamental feature of simulation tools that is often mentioned in literature. The UIM of the interface incorporates expressing information using presentation techniques and media to achieve communicative purposes and support users performing their task (Maybury and Wahlster 1998). This criterion incorporates two main features. The first feature is the 'usability' and the second is the 'information management'. The 'usability' incorporates the functional operation of a tool including representation of input, presentation of output, navigation and control. Usability also entails the learning curve, documentation, online help, look-up tables and error diagnostics. The word 'information management' is the second part of this criteria that is responsible for allowing assumptions, using default values and templates to facilitate data entry (Donn 2001). Issues such as input quality control, comparative reports creation, performance benchmarking, data storage, user customization, input review as well as input modification are all considered as part of the information management features of any simulation interface (Crawley, Hand et al. 2005).

\subsubsection{Integration of Intelligent design Knowledge-Base (IIKB)}

The second criterion that is frequently mentioned in literature is the Integration of Intelligent design Knowledge-Base within the tool. This criterion trades in other realms under such names 
as design decision support and design optimization. This criterion incorporates two main features, the 'knowledge-base' (KB) and the 'intelligence'. The KB supports decision making and provides quantitative and qualitative advice regarding the influence of design decisions (Yezioro 2008, Ellis and Mathews 2002) (Lam, Wong et al. 1999). Integrating a Knowledge Base in a tool can be in the form of pre set building templates, building components, heuristic/prescriptive rules or procedural methods for determining appropriate installation for building codes compliance. This includes design guidelines, case studies, strategies etc. Another very practical ramification of IIKB is the 'intelligence' part. The intelligence entails finding quantifiable answers to design questions in order to create context specific analysis, evaluate complex design strategies, optimize design solutions, engage 'what if' scenarios, verify compliance and analyze life cycle (LC) and economical aspects. Intelligent BPS tools can perform parametric analysis identifying key design parameters, comparing various concepts, ranking and even generating semi-automatically design alternatives ((Bambardekar and Poerschke 2009, Hensen 2004). Thus, the IIKB is one of the most important selection criteria of BPS tools in the future.

\subsubsection{Accuracy and Ability to simulate Detailed and Complex building Components (AADCC)}

Under this criterion aspects are classified regarding the validity and quality of simulation models and their resolution. This is a fundamental criterion that is based on analytical verification, empirical validation and comparative testing of simulation (ASHRAE, 2008; Judkoff, 1995). Thus the term 'accuracy' is concerned with all the aspects connected to empirical validation, analytical verification and calibration of uncertainty, as defined by IEA and BESTEST procedure, in order to provide liability and a level of quality assurance to the simulation results (Judkoff, 1995). The other part of this criterion deals with the ability to simulate complex 
building components with high model resolutions. For example, simulating in detail the performance of passive design strategies, renewable energy systems, HVAC systems, energy associated emissions, cost analysis and life cycle cost analysis (LCCA). In addition to green roofs, double skin facades, chilled beams, atria, concrete core conditioning etc. Therefore, this criterion is defined as a pervasive and persistent criterion for tool selection and evaluation.

\subsubsection{Interoperability of Building Modelling (IBM)}

Next, we define the Interoperability of Building Modelling that corresponds to the ability to manage and communicate building data between collaborating firms and within individual companies design and construction. The IBM is a fundamental criterion for assessing BPS tools because it allows multidisciplinary storing and sharing of information with one virtual representation. Significant research and development has been carried out to integrate simulation tools with computer aided design (CAD) applications. Also industry foundation classes (IFC) standard evolved as an international information exchange standard that allows project participants to work across different software applications (Bazjanac 2003; Bazjanac 2004). The latest emerging application is the building information modelling (BIM), a model-based technology that is linked to a project information database (AIA 2007a\&b). Thus, one of the important BPS tools selection criteria is IBM. IBM is important to assure interoperability by fluidizing model representation, allowing low and high resolution building models that correspond to all design phases and allow a design team based model.

\subsubsection{Integration of tools in Building Design Process (IBDP)}

The Integration of tools in Building Design Process criterion is another criterion that is becoming frequently mentioned in BPS literature. With the growing importance in integrating BPS tools during the whole building design delivery process simulation should be used as an 
integrated element of the design process (Augenbroe 1992; Mahdavi 1998 and Morbitzer 2003). BPS tools should be adaptive and 'design process centric' as proposed by many experts (Hayter, Torcellini et al. 2001; Mendler, Odell et al. 2006; De Wilde and Prickett 2009). This emerging criterion is important in selecting BPS tools because it verifies the ability of the tool for adaptive use for various purposes, by different users and at different design stages (Tianzhen, Jinqian et al. 1997). Thus the IBDP became a basic criterion for BPS tools selection and evaluation.

In this section, five criteria have been defined reflecting the mainstream in simulation community. The inherent limits to a synopsis of the five influential selection criteria are apparent. However, these five criteria are more linked than the categorization suggest. In order to guarantee plausible and persuasive selection criteria, this categorization hypothesis forms the basis for two survey questionnaires. The surveys provide the opportunity to test and critically judge the classification of the five selection criteria. The next section explores the questionnaires design and execution.

\section{Questionnaire:}

To test the validity of the literature review and the classification hypothesis, the major five selection criteria were used to form the basis of the survey questionnaire. The hypothesis assumes that any BPS tool user's concern can be classified under one of the five criteria. Also several questions were formulated, for every selection criteria, testing the relative importance of relevant sub-issues that have been classified and identified in the literature review. The questionnaire was dedicated to gathering information from beginner simulation tool users including architects, engineers, designers and recently graduated students who are concerned with sustainable building design in the USA. The survey aimed to probe the users' perception of 
the most important criteria on the use and function of ten major USA market tools during the design decision process.

Prior to launching the survey the authors set up an online test version. Comments and suggestions were requested from peer reviewers. Reviewers were asked to revise the questionnaire and provide critical feedback in order to optimize the structure, clarity and relevance of the questionnaire before posting the final version online. Also reviewers were asked to screen and list top-ten BPS tools, using the U.S. BESTD list and the comparison study by Crawley et al in (Crawley, Hand et al. 2005). The selection had to represent an overview of state of the art BPS tools used by architects and engineers in the USA (DOE 2010). The list was narrowed down to those tools that are used for evaluating and analyzing the building energy performance. Lighting and CFD simulations have been excluded because they are disconnected from the energy and thermal performance realm. As a result, ten tools namely, ECOTECT ${ }^{\circledR}$ (Autodesk 2008; Autodesk 2009), HEED ${ }^{\circledR}$ (UCLA 2008; UCLA 2009), Energy $10^{\circledR}$ (E10) (NREL 2005; NREL 2009), DesignBuilder ${ }^{\circledR}$ (DB) (DesignBuilder 2008; Design Builder 2009), eQUEST $^{\circledR}$ (LBNL and Hirsch 2009; LBNL and Hirsch 2009), Green Building Studio ${ }^{\circledR}$ (GBS) (Autodesk 2008; Autodesk 2009), IES Virtual Environment Viewer ${ }^{\circledR}$ plug-in (IES VE plug-in) (v.5.8.2) and SketchUP/Open Studio ${ }^{\circledR}$ (OS) plug-in (Google 2009; NREL 2009) were selected plus ‘raw’ DOE-2 ${ }^{\circledR}$ (LBNL and Hirsch 2008; LBNL and Hirsch 2009) and EnergyPlus ${ }^{\circledR}$ (EP) (DOE 2009; DOE 2009).

\subsection{Survey 1}

The first survey was launched between mid December 2008 and mid February 2009 including 22 questions. The questionnaire was structured in three parts. The first part was screening the background and experience with BPS tools of the respondent. The second parts of the survey 
focused on the (1) UIM of the interface. The (2) IIKB and (5) the IBDP were merged together in the third part.

\subsection{Survey 2}

The second survey was launched between mid July 2009 and mid October 2009, including 16 questions. Both surveys were structured to include the same introduction entailing eight questions. The second and third part of the survey focused on the following key criteria: (3) IBM, (4) AADCC.

The first survey was closed after two months. The second survey was closed after three months to ensure a balanced participation compared to the first survey sample. The user's responses were stored and results summaries were automatically generated. The first survey attracted over 800 interested visitors. However, the automatic report filtering generated only 481 eligible respondents. The second survey attracted over 750 interested visitors with 417 eligible respondents. Many respondents opted not to complete the survey until the end. The responses came from various internet protocol (IP) of users that answered the survey. IP responses from outside the USA and uncompleted responses were excluded.

\section{Results:}

This section presents some of the survey results. Each survey included eight introduction questions and a set of questions for two selection criteria. For this paper, representative questions that reflect the most important findings are selected. The complete results are presented and can be found in the final study report (Attia, 2010). Prior to analyzing the survey results it is very important to question the statistical significance of the survey. In fact, the questionnaire is based on an open sample and therefore, the four respondent sample groups cannot be proven to be representative for the engineering or architecture community. However, the number of 
respondents of both surveys was quite reasonable, allowing the identification of patterns and conduct cross-discipline analysis (Pilgrim, Bouchlaghem et al. 2003).

\subsection{How do you describe your current position?}

This question allowed the respondents to choose from 12 available categories including architect, engineer, architecture or engineering designer, interns, educators, graduate student and undergraduate student. Remarkably under the "Other” option a number of construction management professionals and students provided complete responses. However, in order to conduct the inter-group comparison between architects and engineers only all categories were binned into two main groups. Participants that did not fall into any of the 12 categories were excluded. This step was necessary in order to detect any disciplinary difference between architects and engineers. Figure 03 shows the number of respondents who fully completed the survey, grouped for each survey. The sample size of each group in both surveys was almost equal. Thus, we could say that on average the magnitude of each group is balanced which allows us to compare votes.

4.2 What are the parameters you focus on the most, when performing simulation?

Both groups were asked to classify and rank 15 design parameters. There was an agreement from both groups that the energy consumption is the most important parameter as shown in Figure 04 and Figure 05.

\section{Part I - Usability and Graphical Visualization of the Interface}

4.3 Indicate how important you think each of the following objectives is, concerning usability and graphical visualization of the interface

As shown in Figure 06, 23\% of the architects and 26\% of the engineers agreed that the graphical representation of the output results is the most important feature concerning the UIM 
of the interface. There was consensus among both groups that the flexible use and navigation is the second most important feature followed by the graphical representation of the results in 3D spatial analysis. Both groups agreed that the easy learnability and short learning time of simulation tools is the least important feature.

4.4 Indicate how important you feel each of the following objectives is, concerning information management of the interface

As shown in Figure 07 engineers identified the quality control of simulation input as the most important feature concerning information management of the interface. However, architects prioritized the ability to create comparative reports for multiple alternatives above the input quality control.

\section{Part II - Integration of Intelligent Knowledge-base}

4.5 Indicate how important you feel each of the following objectives is, concerning intelligent knowledge-base and design process

Figure 08 shows architects are prioritizing the ability to support the decision making while engineers are favouring the ability to examine the sensitivity and uncertainly of the design parameters. The number of architects who chose the ability to embrace overall design during most design stages is three times the number of engineers. Despite the fact that the total number of architects is 249 versus 232 engineers', the comparison is valid and a clear difference can be identified.

\section{Part III - Accuracy of the tools}

4.6 Indicate how important you think each of the following objectives is, concerning tools accuracy

Figure 09 shows architects' first preference (40\%), which is the confidence to create real sustainable design. The second priority of architects (28\%) is the ability to provide accurate and 
realistic results followed by (18\%) the ability to provide validated performance measures. The ability to calibrate the uncertainty (8\%) and the high resolution of simulation model (6\%) were the least important criteria. On the other hand, most engineers (31\%) agreed that accurate and realistic results are the most important feature concerning tools accuracy. The second sub criterion (29\%) is the ability to provide validated performance measures to support design decisions. The third sub criterion (21\%) is the ability to calibrate uncertainties. The ability of BPS tools to create real sustainable results $(10 \%)$ and the high resolution of the simulation model (9\%) are the least important criteria.

\section{Part IV - Interoperability of Building Model}

4.7 Indicate how important you think each of the following objectives is, concerning interoperability of the building model

Figure 10 shows architects' and engineers' priorities. As the most important objective (39\%), architects chose the ability to exchange models with 3D drawing packages such as SketchUp and 3DS Max. The second choice was for the exchange of models with CAD programs (25\%). The exchange of models for multiple simulation domains and the exchange of model with MEP drawing packages came in last with almost no difference (18.3\% and $17.8 \%)$ in preference. On the other hand, engineers prioritized different sub criteria. The most important sub criterion was the ability to exchange model with MEP drawing packages such as Revit and Bentley products (45\%). In second place (35\%), came the ability to exchange models for multiple simulation domains. In third place (18\%), engineers voted for the ability of exchanging models with CAD programs. The least important feature was the ability to model with 3D drawing packages with less than $2 \%$ of the votes. 


\section{Part V - Most important features of a simulation tool}

4.8 What are the most important features of a simulation tool?

This is one of the most important questions of the survey. The question was repeated in both surveys aiming to benchmark and rank the importance of major selection criteria for BPS tools. The question was designed on purpose and positioned at the end of the survey to guarantee that respondents understood the meaning of the four compared criteria with minimum confusion. After compiling the answers of both samples in one graph, as shown in Figure 11, we found the following: Architects in both surveys agreed to prioritize the IIKB over the UIM of the interface and even the AASDC. The IBM was found to be the third important selection criteria while the AADCC came in last place. On the other hand, engineers agreed to prioritize AADCC. The UIM and IIKB came in second and third place respectively. The IBM was the least important criterion to select a BPS tool.

\section{Part VI - Evaluating and ranking ten tools: architects versus engineers}

The ranking of tools is the result of a compilation of 7 question answers. Each question was followed by a follow up question asking the participants to rank the tools according to the question's sub criteria. Participants could choose more than one simulation tool. Results were classified and binned into two groups. Figure 12 illustrates the number of votes received for every tool. Among architects there is an agreement to rank IES VE plug-in (85), ECOTECT (82) and DB (72) on top. The second category contains GBS (62), E10 (58), eQUEST (52) and HEED (50) with less agreement among respondents and SU OS plug-in, EP and DOE-2 are at the end of the list. Engineers ranked the ten tools differently. DB (85) and EP (82) came in the first category. The second category included eQUEST (72), DOE-2 (70), IES plug-in (68) and OS plug-in (65). In the last category came GBS (40), E10 (25), ECOTECT (20) and HEED (4). 


\section{Part VII - General comments}

An open question followed every part of the questionnaire in order to allow respondents to share their thoughts and comments. A selection of the comments and their frequency is classified as follows:

4.9 What other features should be improved in the future development of BPS tools concerning friendliness and UIM of the interface?

Architects' comments include:

- Allowing debugging (12)

- Default templates, but also front -and-centre delineation, ability to modify those templates (1)

- Error-checking to ensure models are correct (3)

- User friendly HVAC templates (5)

- 3D visualization of design strategies(6)

- Graphical representation of design parameters (use the language of architects) (18)

- Easy searchable building input database (1)

- Balance between extensive (deep) and quickly (basic) input data (4)

- Ability to add/remove building features with ease and ability to make custom reports (3)

Engineers’ comments include:

- Provide echo-print of input in a readable format (1)

- Mapping data entry trees and limiting access to relevant paths to objectives (2)

- Have a huge amount of customizability in terms of output. (e.g. selecting output format, delimiters, etc., so that one could optimize output for input into any visualization package one wished with scripting capabilities (6)

- Transparent default options, more background information through links (11)

- $\quad$ Support database management (2)

4.10 What other features should be improved in the future development BPS tools concerning the IIKB?

Architects' comments include:

- Scenario/Alternative based design approach (15)

- Define most influential design parameters in early design phases and their sensitivity range (8)

- Assisting decision making process through guidance (6)

- Cases of low-cost, ultra energy efficient buildings and LEED buildings (24)

- Guidance and rules of thumb on passive design (8)

- Passive system simulation, simulation of traditional passive design strategies and freerunning buildings (8) 
- Assist decision on materials to be used in the design (5)

- Conform to codes and rating systems (13)

- Large design component libraries e.g. double façade, green roof (4)

- Contextual material property database (2)

- The ability to utilize ASHRAE's intermittent occupancy calculation or air quality calculation based upon intermittent occupancy and advanced filtration (2)

- $\quad$ Comprehensive HELP menu (7)

Engineers' comments include:

- Multi-objective design optimization (12)

- Assistance with control settings (e.g. air flow and set point temperatures) (11)

- Interface with manufacturers' information - e.g. standard formats for MEP equipment, windows, etc that can be imported directly (7)

- Introducing optimization models to identify optimal design considering performance and cost (7)

4.11 What other features should be improved in the future development of BPS tools concerning the AADCC?

Architects' comments include:

- Renewable energy systems calculators should be a part of the package and tied into the overall project's energy performance (3)

- BESTESTs until BPS tools can be able to certify Passive Houses (2)

- Passive strategies such as green roofs and natural ventilation (8)

- Embodied energy calculation (1)

- Ability to easily simulate essential elements (i.e. fin overhangs) in sufficient detail (2)

- Building envelope design optimization (12)

- Consider natural ventilation to combine with HVAC system design (11)

- Inform users as to the cost impacts of energy reduction measures (1)

Engineers' comments include:

- Real-time results, parametric feedback (3)

- Collecting realistic data from cases to establish performance based data sets (6)

- Optimized for small, ultra-efficient buildings (2)

- Data to measure and describe uncertainty (9)

- Model thermal mass, air-to-air heat exchangers, passive and active solar gains, or the most efficient lighting and passive drying options, radiant slabs/beams, ground source HX, heat recovery chillers etc, (15)

- Indication of the degree of error that should be tolerated in the results (2)

- Error estimate of models for validation and acceptable error range (1)

- Gather post occupancy data feedback and implement into the software (1)

- Be built on an underlying database to aid in benchmarking (1)

- Perform trade-off analysis and an LCA tool to compare different options (2) 
- Wider range of HVAC and natural ventilation modelling techniques (13)

- Test cases representing buildings after construction (2)

- Allow more than one system per zone (3)

4.12 What other features should be improved in the future development of BPS tools concerning IBM?

Architects’ comments include:

- Allowing organic modelling of curved volumes and non-cubical zones (1)

- Allowing input from multiple modelling programs (sketch up, rhino, 3dmax, Revit, etc) easily and with minimal error (3)

- Ability to merge architectural CAD drawings into respective thermal zones (11)

- Change building geometry without having to re-enter all data from scratch (8)

- Importing of detailed geometries with more accuracy and all layers being correctly imported in energy simulation software (11)

Engineers' comments include:

- One common language like gbXML (but more robust) to become an open standard, third party organizations need to create a standard language (1)

- 3D parametric modelling (3)

- Full IFC compliance: Import / Export equally robust, all elements that can be modelled must be able to be exported / imported in IFC with all relevant data (at a minimum name, type, size, material) - this includes MEP as well as Architecture \& Structure (2)

- library of building components and building assemblies in a common format or formats (GBXML, IDF) (3)

- Components that include data that describe how they behave (5)

\section{Discussion:}

This section interprets and analyzes the data generated through the survey. 445 architects and

453 engineers responded to this survey and formed a snapshot of the preference and current use

of ten BPS tools. The open end questions generated comprehensive and abundant wish lists for tool developers. The research findings are discussed under two headings. The first heading discusses the gap between architects and engineers throughout the respondents' answers. The second heading discusses the tools selection criteria and users needs. 


\subsection{The gap between architects and engineers}

By analyzing and comparing the responses in a cross disciplinary way we came to this generalization. A wide gap exist between architects and engineers as BPS tools users. Out of nine questions, architects and engineers agreed only two times. By interpreting the survey results and in particular question 4.2 and 4.8 we found proof for this evident gap. For example, answers of question 4.2 in Figure 04 show that architects are concerned with architectural design issues including shading, passive heating, orientation, natural ventilation and geometry. HVAC systems and controls were ranked by architects as the least important. On the other hand, engineers ranked HVAC system, controls, comfort, glazing openings and insulation respectively in the top in Figure 05.

Answers of question 4.8 show a tendency among architects to prioritize the Integration of Intelligent Knowledge-base (IIKB). According to Figure 11 there is a tendency among both surveyed architect groups to classify the IIKB on top (31\% and 34\%) exceeding even the votes for the UIM of the interface (28\% and 30\%). Question 4.9 reveals examples of architects' expectations from the IIKB. The findings are new when compared to previously published work that confirms architects’ preference for better Usability and Information Management of BPS interfaces (Attia 2009, Punjabi 2005, Van Dijk, 2002, Holm, 1993, Mahdavi, 2003).

On the contrary, engineer's top BPS tools selection criterion is the Accuracy and Ability to simulate Detailed and Complex building Components (AADCC). Both engineers groups voted for the AADCC (42\% and 42\%). This result is not new and agrees with previous published work that confirms engineers' determination to attain maximum possible accuracy and validation of simulation models. Question 4.11 reveals examples of engineers' expectations from the AADCC including issues related to model resolution, input quality assurance and calibration (Donn 2001; 
Augenbroe 2002; Pilgrim, Bouchlaghem et al. 2003; Hensen and Radošević 2004; Ibarra and Reinhart 2009; Tian, Love et al. 2009).

The gap becomes more evident by reviewing the tool ranking results shown in Figure 12. In fact, comparing and evaluating the tools in an absolute and valid way was not the aim of this study. Any tool comparison study has a short life time because each tool keeps improving and has its advantages and limitations. However, the comparison allowed us to test the selection criteria and understand users' tendencies and preferences. For example, architects ranked IES VE plug-in, ECOTECT and DB in the top because they provide a friendly graphical user interface (GUI) with various default templates that allow an easy use and simple information management. The GUI of those tools incorporate a geometrical 3D modeller with various data exchange features. Another reason for selecting IES VE plug-in and DB was because their adaptability to be used during different design phases and by different design team members and in particular engineers. However, architects indicated the lack of IIKB systems within the compared tools. In this context, the result is in agreement with Figure 11 which proofs that architects prioritize the IIKB and the adaptive and easy UIM of interfaces. On the other hand, engineers had a different view ranking DB, EP and eQUEST on top. Already DB is a third party graphical user interface for EP, the successor of DOE-2 similar to eQUEST the graphical user interface for DOE-2. Engineers' responses indicate that DB and EP represent the most accurate state of the art BPS tools allowing Accuracy and Ability to simulate Detailed and Complex building Components. For example, DB provides a strong template driven graphical user interface that bridges the difficulties of using 'raw' and text input based on EP files. EP is a transparent tool that includes most features of BLAST and DOE-2 with various simulation capabilities including time steps of less than an hour, modular systems and plant integrated with heat balance-based zone simulation, 
multizone air flow, thermal comfort, and photovoltaic systems. EP also allows data exchange and is under constant development. In this context, engineers ranked the tools according to their accuracy first, which matches with Figure 11, proving that engineers prioritize AADCC.

Figure 12 shows an example of adaptive tools that can be used in cross disciplinary context. Both, DB and IES VE plug-in received the highest percentage of agreement from both groups. The selected tools have a user friendly front-end and run in front of EnergyPlus and IES Apache Simulation engine. This means that it is possible to agree on a common denominator in the field of BPS. Future tools must learn from that how to allow cross-disciplinary design practice where architects and engineers intervene during different design phases and share the same BPS model.

In brief, the survey results show a common pattern that indicates a wide gap between architects and engineers as BPS tools users. The reasons for this gap can be traced in the historical development of both professions during the last century. Since the industrial revolution, with the advancements in the field of sciences and materials, a clear division between both professions became more obvious (Larsen and Tyas 2003). Both groups developed within a mono-disciplinary environment and catered their services within a linear and fragmented building delivery process (Mahdavi 1998). Therefore, tools functionality transcends the knowledge and skills base of only one discipline. Although future tools must match the requirement of design practice and consider the criteria discussed previously, they will not improve the building design practice, if the practice itself or the user does not adapt to accommodate the new functionality offered by BPS tools. The survey revealed that some of the barriers to the use and integration of BPS tools in the design practice lie outside the realm of tool development. Discipline oriented design approaches can no longer achieve exceptional 
performance. In fact, the typical uni-disciplinary design process where the architect and engineers work in separate islands and with no performance goals cannot achieve the new millennium objectives. However, discussing the ways of bridging this gap is beyond the scope of this study. Thus, the study highlights the main difference and preference of both groups allowing a better understanding of the problem.

\subsection{Tools Selection Criteria and users needs}

This section is intended to assist in the review and testing of the five selection criteria for BPS tools. Does the classification reflect the major interests and concerns of respondents? The following paragraphs answer this question.

Respondents’ comment to the open questions (Part VII) provided a rich source on the setting and justification of the five selection criteria. Every comment listed in Part VII was checked across one of the five criteria. Interpreting the results showed that no comment fell outside the five criteria. However, for every criterion there were some missing features that were not included in the questionnaire. The major missing features are listed under the corresponding criterion.

\subsubsection{Usability and information management of the interface (UIM)}

Concerning the UIM of the interface, respondents put forward two missing features. The first is the ability to provide transparent default options and map data entry trees. The second feature is the tool adaptability to different user types and design phases. Further work, is required to allow tracing background information behind assumptions. Moreover, tools should include adaptive GUIs. An adaptive interface will strike a balance between extensive and basic data input in relation to the user type and skill level. The GUI should be adaptive and flexible to improve the 
usability, allow simple and basic data entry choices for non specialists, and detailed data entry choices for specialists.

\subsubsection{Integration of intelligent design knowledge-base (IIKB)}

Respondents would like to increase the tools ability of benchmarking and results comparison. Users suggest the integration of contextual knowledge-base for material properties, design components libraries, occupant behaviour patterns and climatic design characteristics. In the future, the IIKB should inform different users at different design stages to optimize and identify optimum building design strategies.

\subsubsection{The accuracy and ability to simulate detailed and complex building components (AADCC)} Users suggested that further work is required to indicate the degree of error that should be tolerated in the results, the error estimate of models for validation and acceptable error range, describe uncertainty with the data model, algorithms used and their limitations. There is a need for higher model resolution/detail and better model assumptions that allows integrated sub systems design. Respondents identified a gap between predicted and real energy use. Users suggest more adaption to the complexities of the real life designs and climatic conditions. Tools should adopt post-construction monitoring and verification exercises to provide opportunities to calibrate models and serve to help understand the design assumptions.

\subsubsection{Interoperability of building modelling (IBM)}

Users suggest one common language like gbXML or CAD to become an open standard and full IFC (BIM) compliance. Users are dissatisfied with the difficulty of merging geometric models and thermal models with full zone representation. Architects pointed to importance of the interoperability of building modelling for small scale projects. Interoperability should suite different users and design phases. 


\subsubsection{Integrated building design process (IBDP)}

Despite that the IBDP was not explicitly questioned in the survey respondents answers suggested the IBDP to become the fifth selection criteria. The reason for that is that most existing tools cater for one discipline during one or maximum two design phases regardless from the final product which is the buildings. However, respondents pointed to the importance of having a criterion that evaluates the ability of the tool to be used during the design, commissioning and occupancy phases by different users.

Users need fluid tools that can produce initial results from a rough building representation during early design phases and at the same time allow for detailing of building components during later design phases. In order to integrate BPS tools in the design process, different user interfaces must communicate to different users using their familiar language. Further work is required to better understand the current building design and delivery process, in order to extend the application of simulation to all design phases. The building thermal model should evolve through the design process as the model resolution becomes more specified.

Tools should allow different user types to perform simulations during design process. Tools should cater more to design teams. Respondents suggest that architects have more confidence in tools used by engineers, while engineers have more confidence in tools that facilitate the multidisciplinary approach and can be shared by the design team. Tools that allow the integration and interdisciplinary work were ranked higher than tools that focus on individual and mono-disciplinary work. Finally, the aim of this criterion is to evaluate if the tool can bridge the gaps between the design phases and position itself the centre of the iterative and phased design process. 
Finally, the five criteria were composed to set an initial classification scheme for building performance simulation tools. The general five criteria are summarized in Table 01 . The table can be used to evaluate BPS tools and to capture valuable info for improving the quality of BPS programs. Designers can choose the tools in term of the five criteria. However, several pages are not enough to convey the nuances of various tools selection criteria. In this discussion we showed how the survey results and the respondents' feedback helped in assessing the BPS tools selection criteria. In fact, each of these criteria has its critiques. Nonetheless, the five criteria

presented in this paper form a basis for tools selection criteria. As with many classifications they overlap and are not mutually exclusive.

With the sprawl and diversification of BPS tools in addition to the increasing growth of number of users, it will be helpful to find entities (e.g. professional organisations, private magazines, software developers) that focus on facilitating the selection of tools and comparing them with different users needs, using the five selection criteria. We suggest that IBPSA should fund studies to set standard evaluation and selection criteria of BPS tools. Also more comprehensive surveys of simulation use in the architectural and engineering fields should be funded.

\section{Conclusions:}

This study identifies architects and engineers' requirements and selection criteria for BPS tools. The five criteria presented in this paper continue to resound and form the basis of much scholarly and professional activity. The survey results provide an overview of the criteria that need to be addressed by developers to improve the uptake of simulation practice. Tool developers should tap into those wish lists and understand the different perspectives and needs of architects and engineers. Addressing these criteria will require interdisciplinary research in the 
field of building simulation research and the development of design process management (De Wilde and Prickett, 2009). In order to improve the uptake of simulation practice, within a rapidly growing BPS tools environment, we believe that the BPS community has to set a uniform definition of tools selection criteria and specifications. On the other hand, developers might create metrics to analyze the costs and benefits of using BPS tools. This will accelerate and improve the BPS practice.

This paper also provides an indication of tendencies among 445 and 453 surveyed architects and engineers. The analysed survey results show a wide gap between architects and engineers. While developers can use the survey results to improve their tools and create an innovative bridge between architecture and engineering both groups have to work together to bridge their interdisciplinary gap at several levels.

The next generation of BPS tools has to direct its development within the gestalt of the UIM, IIKB, AADCC, IBM and IBDP. Architects and engineers will design buildings using BPS tools which are very adaptive, accurate and that can predict, during all design stages, the energy consumption of high performance buildings. BPS will be at the heart of designing and building high performance buildings in order to inform the design process and evaluate the impact of design decisions. BPS offers a common ground, a platform to support the collaboration between architects' and engineers. Most importantly, pledge the development of sustainable buildings.

\section{Acknowledgements}

The authors express their thanks to all respondents who participated in the survey and appreciate their valuable comments and feedback. The authors thank Adma Hirsch (NREL) and Jikke Reinten (TU-Eindhoven) for comments on earlier versions of this article. This paper is part of an ongoing $\mathrm{PhD}$ research funded by the Université catholique de Louvain.

\section{References}

AIA, 2007a. Integrated Project Delivery: A Guide. Available from: http://www.msaipd.com/IPD_Guide_2007.pdf [Accessed April 2010]. 
AIA, 2007b. Interoperability in the Construction Industry [online]. Available from: http://construction.ecnext.com/mcgraw_hill/includes/SMRI.pdf [Accessed April 2010].

ASHRAE, 2008. Standard method of test for the evaluation of building energy analysis computer programs. Atlanta, Ga.: American Society of Heating, Refrigerating, and Air-Conditioning Engineers.

ASHRAE, 2009. ASHRAE Handbook. Fundamentals. [Inch-pound ed. Atlanta, Ga.: American Society of Heating, Refrigerating, and Air-Conditioning Engineers.

ATTIA, S. et al. 2009. "Architect Friendly": A comparison of ten different building performance simulation tools. ed. BS2009 Proceedings, Glasgow, Scotland.204-211.

ATTIA, S., 2010. Building Performance Simulation Tools: Selection Criteria and User Survey. Architecture et Climat, Louvain La Neuve: Université catholique de Louvain, 1-29 Available from: http://wwwclimat.arch.ucl.ac.be/s_attia/Attia_BPSTools_SelectionCriteriaUserSurvey_Rreport.pdf [Accessed April 2010].

AUgenBROE, G. 1992. Integrated Building Performance Evaluation in the Early Design Stages. Building and Environment, 27(2), 149-161.

AUGENBROE, G. 2002. Trends in building simulation. Building and Environment, 37, 891 - 902.

AUTODESK, 2008a. ECOTECT v5.60.

AUTODESK, 2008b. Green Building Studio v3.3.

AUTODESK, 2009a. ECOTECT.

AUTODESK, 2009b. Green Building Studio [online]. Available from: https://www.greenbuildingstudio.com/ [Accessed November 2009].

BALCOMB, J., 1992. Passive solar buildings. Cambridge, Mass.: MIT Press.

BAMBARDEKAR, S. and POERSCHKE, U. 2009. The architect as performer of energy simulation in the early design stage. ed. BS2009 Proceedings, Glasgow.

BAZJANAC, V., 2003. Improving Building Energy Performance Simulation with Software Interoperability, Interoperability. ed., IBPSA Proceedings, Eindhoven.

BAZJANAC, V., 2004. Building energy performance simulation as part of interoperable software environments. Building and Environment, 39, $879-883$.

BAZJANAC, V. and KIVINIEMI, A. 2007. Reduction, simplification, translation and interpretation in the exchange of model data. ed. CIB 24th W78 Conference Proceedings, University of Maribor.

CLARKE, J., 2009. Integrated Building Performance Simulation: Trends and Requirements. Glasgow: University of Strathclyde.

CLARKE, J., HENSEN, J. and JANAK, M. 1998. Integrated Building Simulation: State-of-the-Art. ed. Indoor climate of Buildings Proceedings, Bratislava.

CLARKE, J. A., 1985. Energy simulation in building design. Bristol [Avon] ; Boston: A. Hilger.

CRAWLEY, D., 1997. Building energy tools directory. ed. IBPSA Proceedings, Prague, 300.

CRAWLEY, D., et al. 2005. Contrasting the capabilities of building energy performance simulation programs. ed. IBPSA Proceedings, Washington DC.

CRAWLEY, D. and LAWRIE, L. 1997. What next for building energy simulation-a glimpse of the future. ed. IBPSA Proceedings, Prague.

CRAWLEY, D. B., et al. 2008. Contrasting the capabilities of building energy performance simulation programs. Building and Environment, 43(4), 661-673. 
DE WILDE, P. and PRICKETT, D. 2009. Preconditions for the use of simulation in M\&E engineering. ed. BS2009 Proceedings, Glasgow.

DERU, M. and TORCELLINI, P. 2004. Improving Sustainability of Buildings through a performance-based design approach. World Renewable Energy Congress. Denver, Colorado.

DESIGNBUILDER, 2008. Design Builder v.1.8.1.001.

DESIGNBUILDER, 2009. DesignBuilder [online]. Available from: http://www.designbuilder.co.uk/ [Accessed November 2009].

DOE, 2009a. EnergyPlus [online]. Available from: http://apps1.eere.energy.gov/buildings/energyplus/ [Accessed November 2009].

DOE, U. S., 2010b. Building Energy Software Tools Directory [online]. Available from: http://apps1.eere.energy.gov/buildings/tools_directory/ [Accessed 1 October 2010].

DONN, M., 1997. A survey of users of thermal simulation programs. ed. IBPSA Proceedings, vol. III, Prague, Czech Republic, 65-72.

DONN, M., 1999. Quality Assurance - Simulation and the real world. ed. IBPSA Proceedings, Japan, 1139-1146.

DONN, M. 2001. Tools for quality control in simulation. Building and Environment, 36, 673-680.

DONN, M., SELKOWITZ, S. and BORDASS, B. 2009. Simulation in the service of design - asking the right questions. ed. IBPSA Proceedings, Glasgow, Scotland.

EISENBERG, D., DONE, R. and ISHIDA, L. 2001. Breaking down the barriers: Challenges and solutions to code approval of green buildings. Tucson, AZ.

ELLIS, M. and MATHEWS, E. 2002. Need s and trends building and HVAC system design tools. Building and Environment, 37, 461-470.

ELLIS, P., TORCELLINI, P. and CRAWLEY, D. 2008. ENERGY DESIGN PLUGIN: AN ENERGYPLUS PLUGIN FOR SKETCHUP. ed. SimBuild Proceedings, Berkeley, California.

General Contractors, 2001c. Nonresidential Buildings, Other Than Industrial Buildings and Warehouses, Farmington Hills.

GOOGLE, 2009. SketchUp Pro7 [online]. Available from: http://sketchup.google.com [Accessed November 2009].

HAND, J. and CRAWLEY, D. 1997. Forget the tool when training new simulation users. ed. IBPSA Proceedings, Prague, Czech Republic.

HAYTER, S., et al. 2001. The Energy Design Process for designing and constructing highperformance buildings. Clima 2000 Proceedings. Napoli.

HEFLEY, W. and MURRAY, D. 1993. Intelligent user interfaces. ed. Intelligent User Interfaces Proceedings , Orlando, Florida, United States.

HENSEN, J., 2002. Integrated Building (and) airflow simulation: An overview. ed. Computing in Civil and Building Engineering, Taipei, Taiwan.

HENSEN, J., 2004. Towards more effective use of building performance simulation in design. ed. Design \& Decision Support Systems in Architecture and Urban Planning Proceedings, Eindhoven: TU/e.

HENSEN, J., LAMBERTS, R. and NEGRAO, C. 2002. A view of energy and building performance simulation at the start of the third millennium. Energy and Buildings, 34(9), 853-855

HENSEN, J. and RADOŠEVIĆ, M. 2004. Some quality assurance issues and experiences in teaching building performance simulation. ed. IBPSA Proceedings, Eindhoven. 
HIEN, W., POH, L. and FERIADI, H. 2003. Computer-Based Performance Simulation for Building Design and Evaluation: The Singapore Perspective. Simulation \& Gaming, 34(3), 457477.

HOLM, D., 1993. Building Thermal Analyses: What the Industry. Needs: The Architect's Perspective. Building and Environment, 28(4), 405-407.

HONG, T., CHOU, S. K. and BONG, T. 2000. Building simulation: an overview of developments and information sources. Building and Environment, 35, 347-361.

HOPFE, C., et al. 2005. Exploration of using building performance simulation tools for conceptual building design. ed. IBPSA-NVL Conference Proceedings, Delft, The Netherlands.

IBARRA, D. and REINHART, C. 2009. Daylight factor simulations - how close do simulation beginners 'really' get? ed. BS2009 Proceedings, Glasgow.

IEA, 2009. IEA Net Zero Energy. Montreal.

JUDKOFF, R. and NEYMARK, J. 1995. International Energy Agency Building Energy Simulation Test (BESTEST) and Diagnostic method. Golden, Colorado: NREL.

KUSUDA, T., 1999. Early history and future prospects of buildings system simulation. ed. IBPSA, Kyoto Japan.

LAM, K., HUANG, Y. and ZHAl, C. 2004. Energy Modeling Tools Assessment For Early Design Phase. Carnegie Mellon University, PA, 1-17.

LAM, K., WONG, N. and HENRY, F. 1999. A study of the use of performance-based simulation tools for building design and evaluation in Singapore. ed. IBPSA Proceedings, Kyoto, Japan, 675-682.

LARSEN, O. P. and TYAS, A., 2003. Conceptual structural design: bridging the gap between architects and engineers. London: Thomas Telford.

LAWSON, B., 1997. How designers think: the design process demystified. Completely rev. 3rd ed. Oxford, U.K. ; Boston, Mass.: Architectural Press.

LBNL and HIRSCH, J. 2008a. DOE v2.2 Building energy use and cost analysis program. Berkeley, CA: LBNL.

LBNL and HIRSCH, J. 2008b. eQUEST v3.61b. Berkeley: LBNL.

LBNL and HIRSCH, J. 2009a. DOE-2 [online]. Available from: http://www.doe2.com/ [Accessed November 2009].

LBNL and HIRSCH, J. 2009b. eQUEST [online]. Available from: http://www.doe2.com/eQUEST/ [Accessed November 2009].

MAHDAVI, A., 1998. Computational decision support and the building delivery process: A necessary dialogue. Automation in Construction, 7, 205-211.

MAHDAVI, A., et al., An inquiry into building performance simulation tools usage by architects in Austria. ed. IBPSA Proceedings, 2003 Eindhoven, 777-784.

MAYBURY, M. T. and WAHLSTER, W., 1998. Readings in intelligent user interfaces. San Francisco, Calif.: Morgan Kaufmann Publishers.

MENDLER, S., ODELL, W. and LAZARUS, M. A., 2006. The HOK guidebook to sustainable design. 2nd ed. Hoboken, N.J.: John Wiley \& Sons.

MORBITZER, C., 2003. Towards the Integration of Simulation into the Building Design Process. (PhD). University of Strathclyde, 1-216-277. 
MORBITZER, C., et al. 2001. Integration of building simulation into the design process of an architecture practice. IBPSA Proceedings. Rio de Janeiro, Brazil, 697-704.

NREL, 2005. ENERGY-10 v1.8.

NREL, 2008. OpenStudio 1.0.2.

NREL, 2009. Energy-10 [online]. Available from: http://www.nrel.gov/buildings/energy10.html [Accessed November 2009].

PAPAMICHAEL, K., et al. 1996. The Building Design Advisor. ed. ACADIA Proceedings, Arizona.

PAPAMICHAEL, K. and PROTZEN, J. 1993. The limits of Intelligence in Design. ed. System Research, Informatics and Cybernetics Rroceedings, Baden, Germany, 1-10.

PEDRINI, A. and SZOKOLAY, S. 2005. The architects approach to the project of energy efficient office building in warm climate and the importance of design methods. ed. IBPSA Proceedings, Montréal, Canada, 937-944.

PILGRIM, M., et al. 2003. Towards the efficient use of simulation in building performance analysis: a user survey. Building Services Engineers, 24(3), 149-162.

PUNJABI, S. and MIRANDA, V. 2005. Development of an integrated building design information interface. ed. IBPSA Proceedings, Montreal, Canada, 969-976.

REINHART, C. and FITZ, A. 2006. Findings from a Survey on the current use of daylight simulations during building design. Energy and Buildings, 38, 824-835.

RIETHER, G. and BUTLER,T. (2008). Simulation space. A new design environment for architects. In 26th eCAADe Conference Proceedings. Muylle M., ed., Antwerp, Belgium, 132-141.

ROBINSON, D. 1996. Energy model usage in building design: A qualitative assessment. Building Services Engineering Research and Technology, 17(2), 89-95.

SCHLUETER, A. and THESSELING, F. 2009. Building information model based energy/exergy performance assessment in early design stages. Automation in Construction, 18(2), $153-$ 163.

SCHON, D., 1985. The Design Studio. London: RIBA.

TIAN, Z., LOVE, J. and TIAN, W. 2009. Applying quality control in building energy modelling: comparative simulation of a high performance building Journal of Building Performance Simulation, 2(3), 163 - 178.

TIANZHEN, H., JINQIAN, Z. and YI, J. 1997. IISABRE: An Integrated Building Simulation Environment Building and Environment, 32(3), 219-224.

TORCELLINI, P., HAYTER, S. and JUDKOFF, R. 1999. Low Energy Building Design - The Process and a Case Study. ASHRAE, 105(2), 802-810.

UCLA, 2008. HEED v.3.0.

UCLA, 2009. HEED [online]. Available from: http://mackintosh.aud.ucla.edu/heed/ [Accessed November 2009].

VAN DIJK, E. and LUSCUERE, P. 2002. An architect friendly interface for a dynamic building simulation program. ed. Sustainable Building, Oslo, Norway.

WARREN, P., 2002. Bringing simulation to application, IEA ECBCS Annex 30. Brimingham.

Weytjens, L., Attia, S et al. (2010) A comparative study of the 'architect-friendliness' of six building performance simulation tools, Sustainable Buildings CIB Proceedings, Maastricht, Netherlands.

Weytjens, L. and Verbeeck, G. (2010) Towards 'Architect-friendly' Energy Evaluation Tools, SimAUD Proceedings, Florida, USA. 
YEZIORO, A. 2008. A knowledge based CAAD system for passive solar architecture. Renewable Energy, 34, 769-779.

\section{Building Energy Software Tools Directory- DOE}

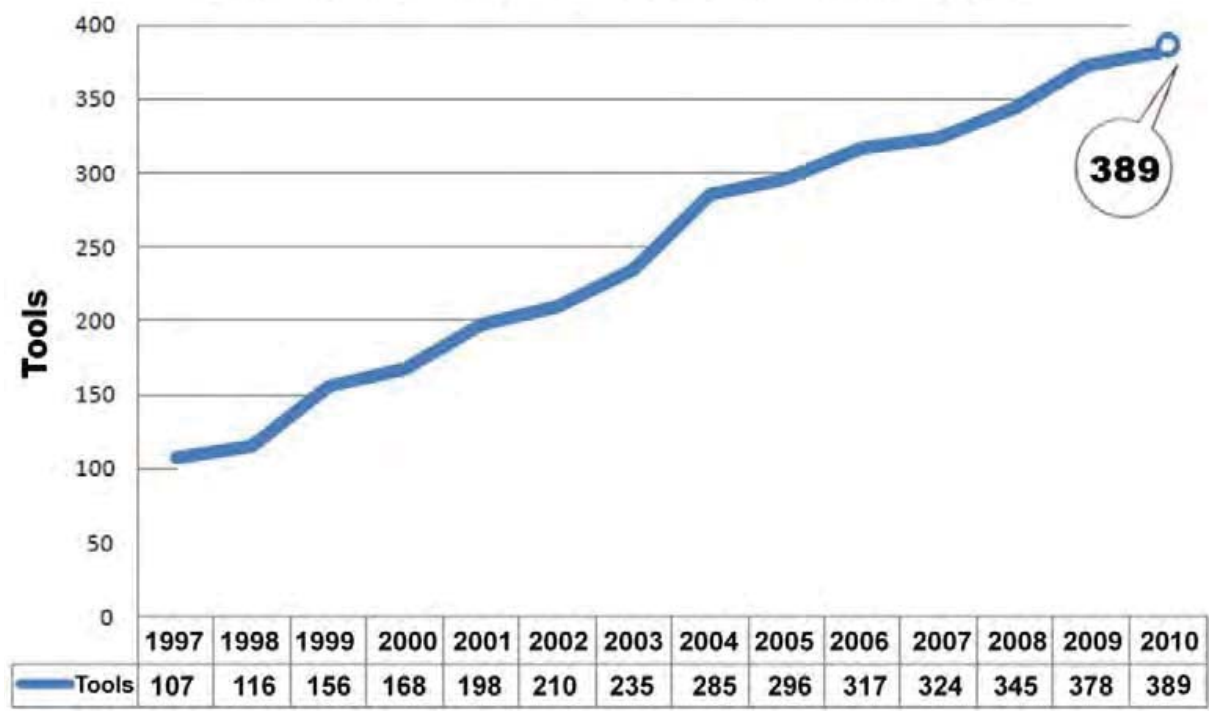

Figure 01, BPS tools developed between 1997- 2010

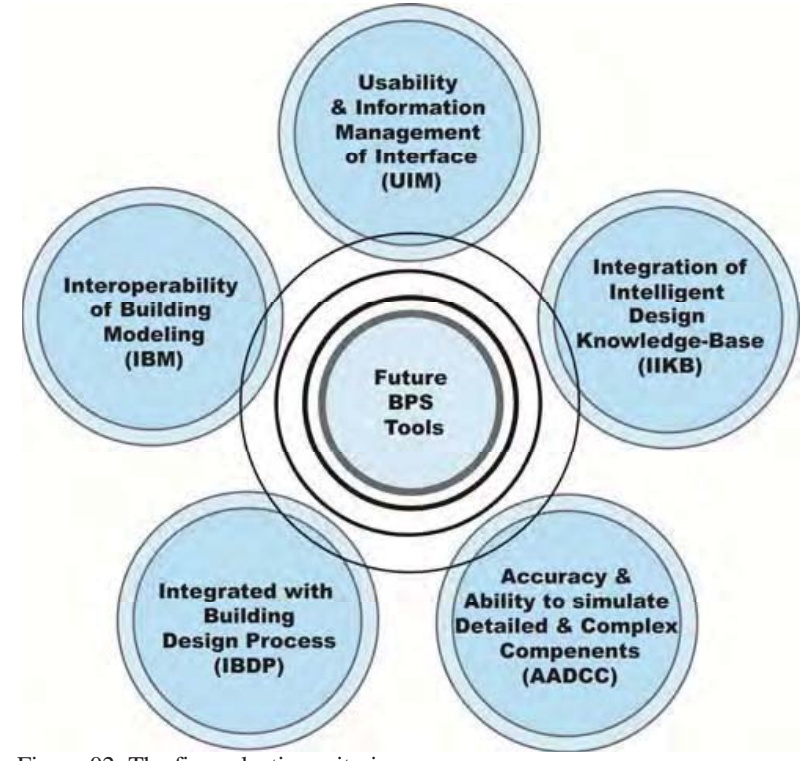

Figure 02: The five selection criteria 
How do you describe your current position?

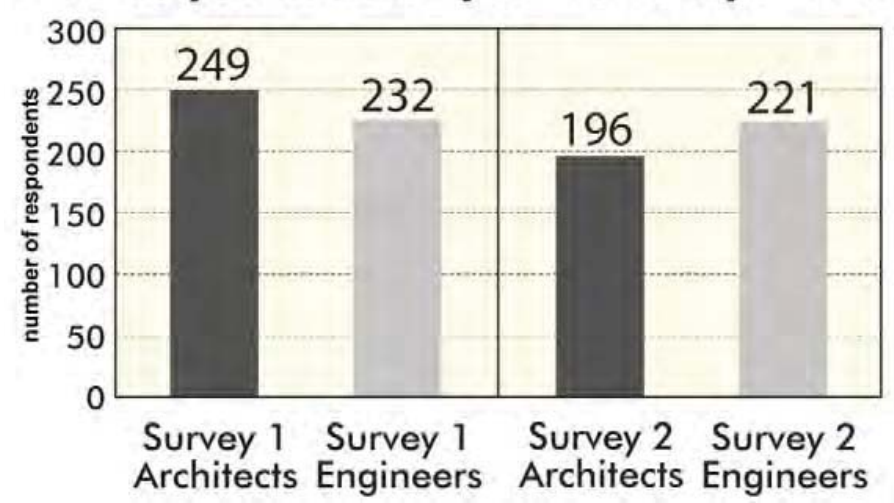

Figure 03: Number of respondents in both surveys

Architects Ranking Parameters According to Importance

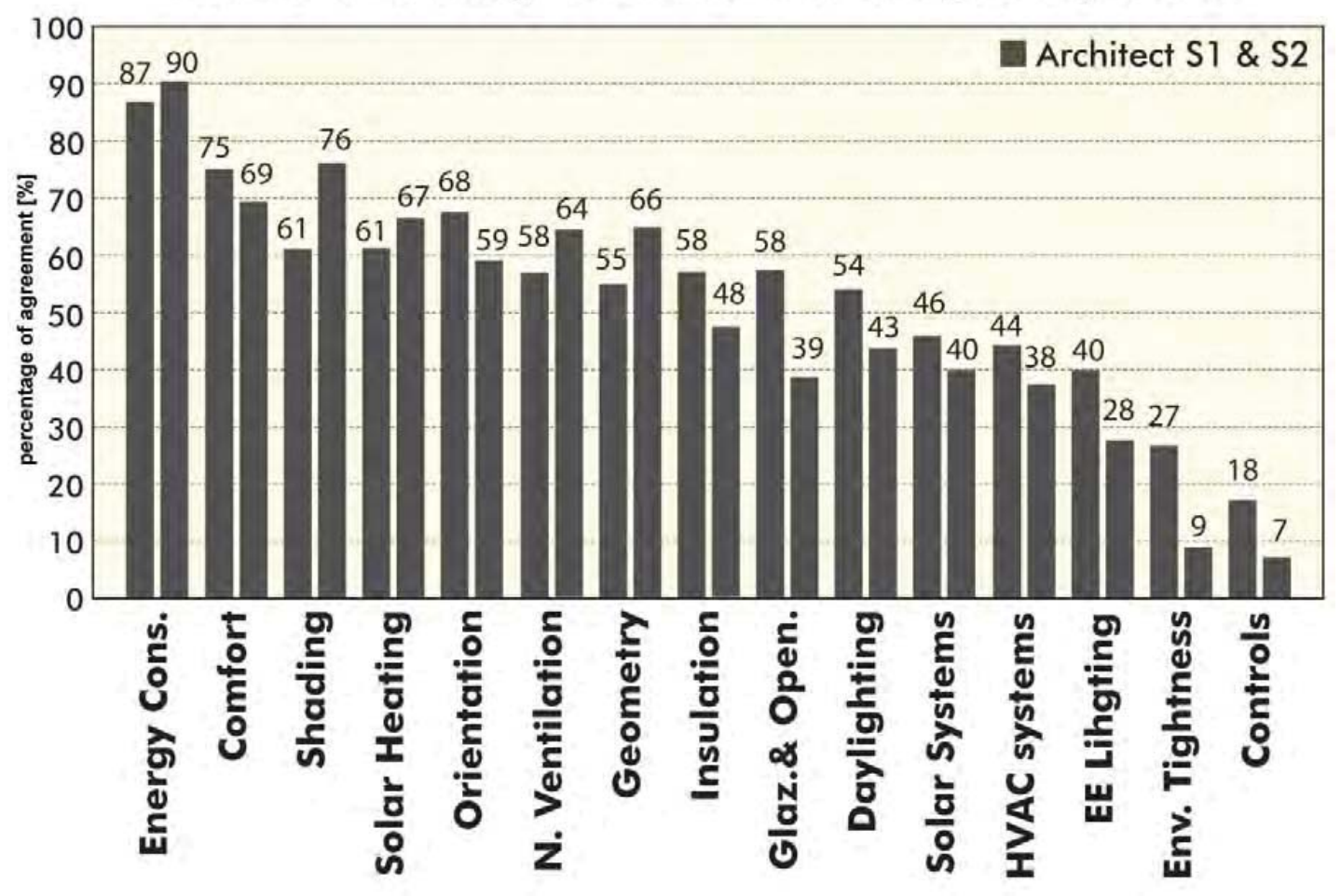

Figure 04: Ranking the importance of output parameters - Architects 


\section{Engineers Ranking Parameters According to Importance}

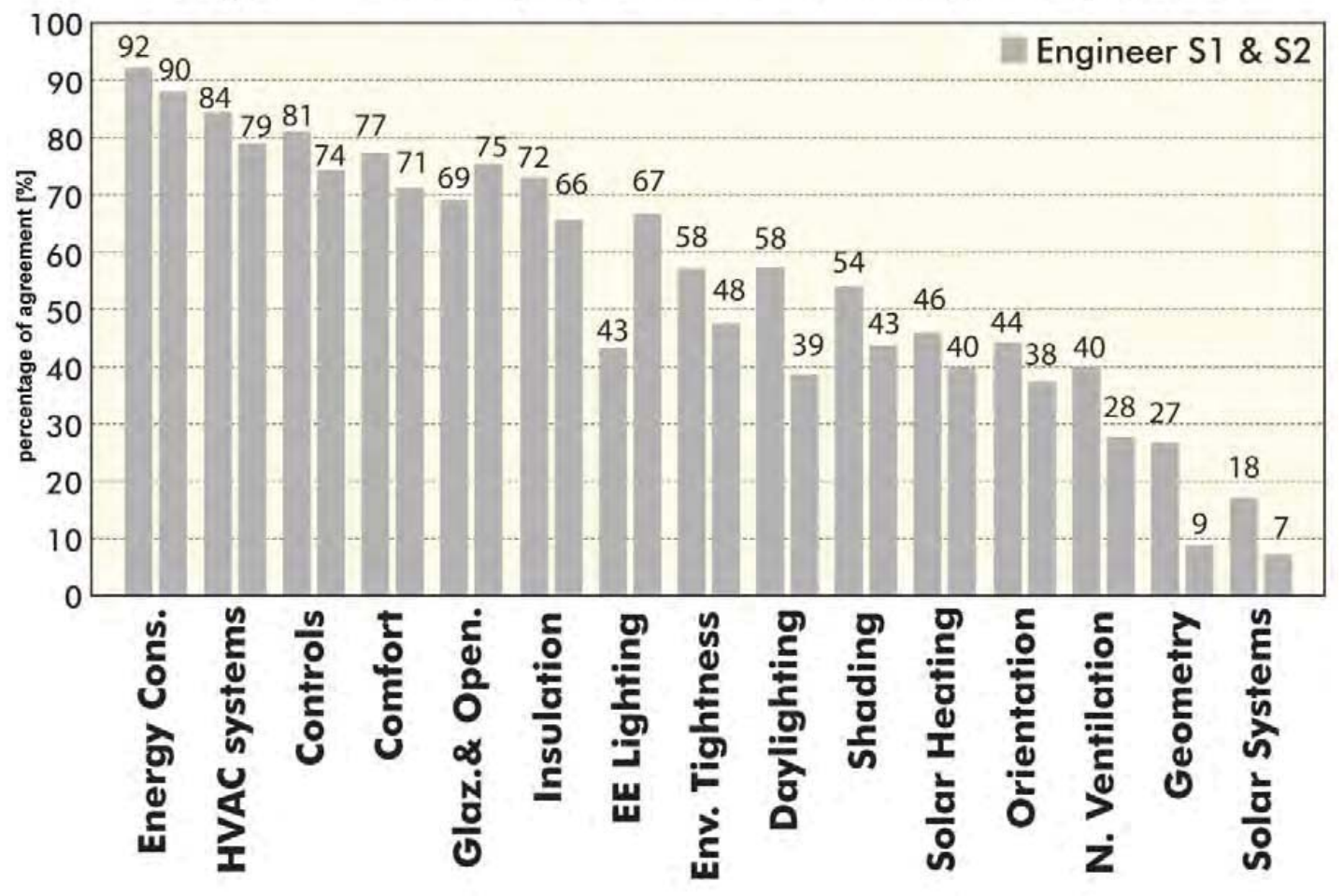

Figure 05: Ranking the importance of output parameters - Engineers

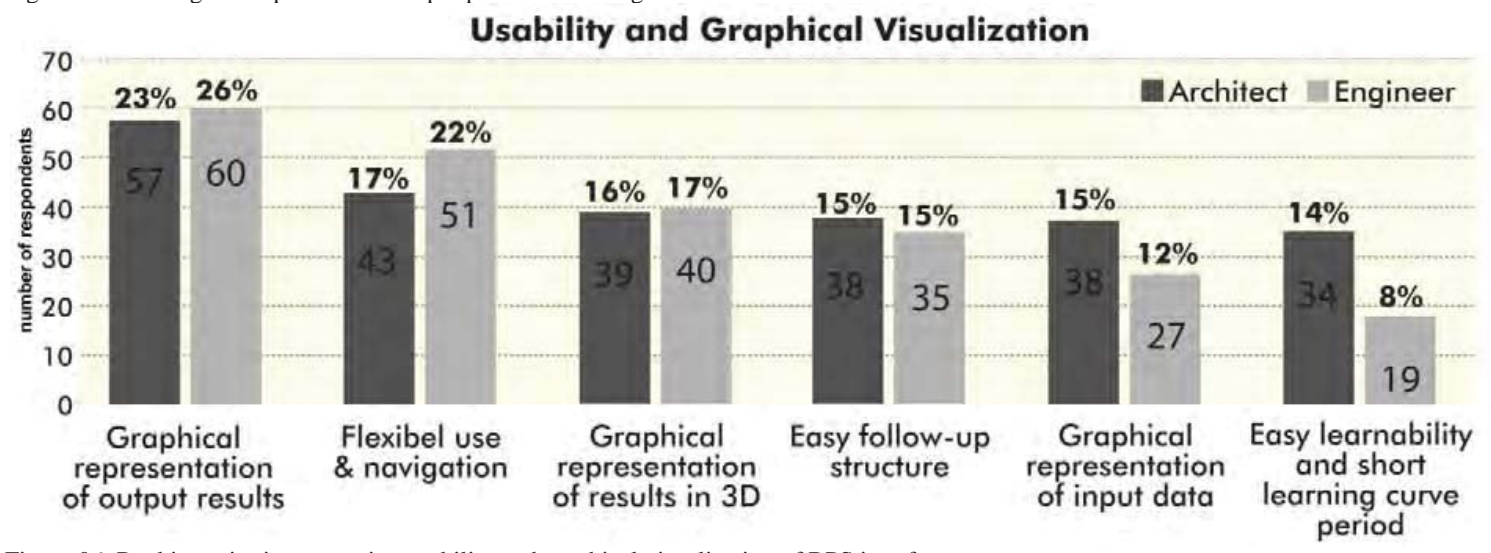

Figure 06: Ranking criteria concerning usability and graphical visualization of BPS interfaces 
Information Management

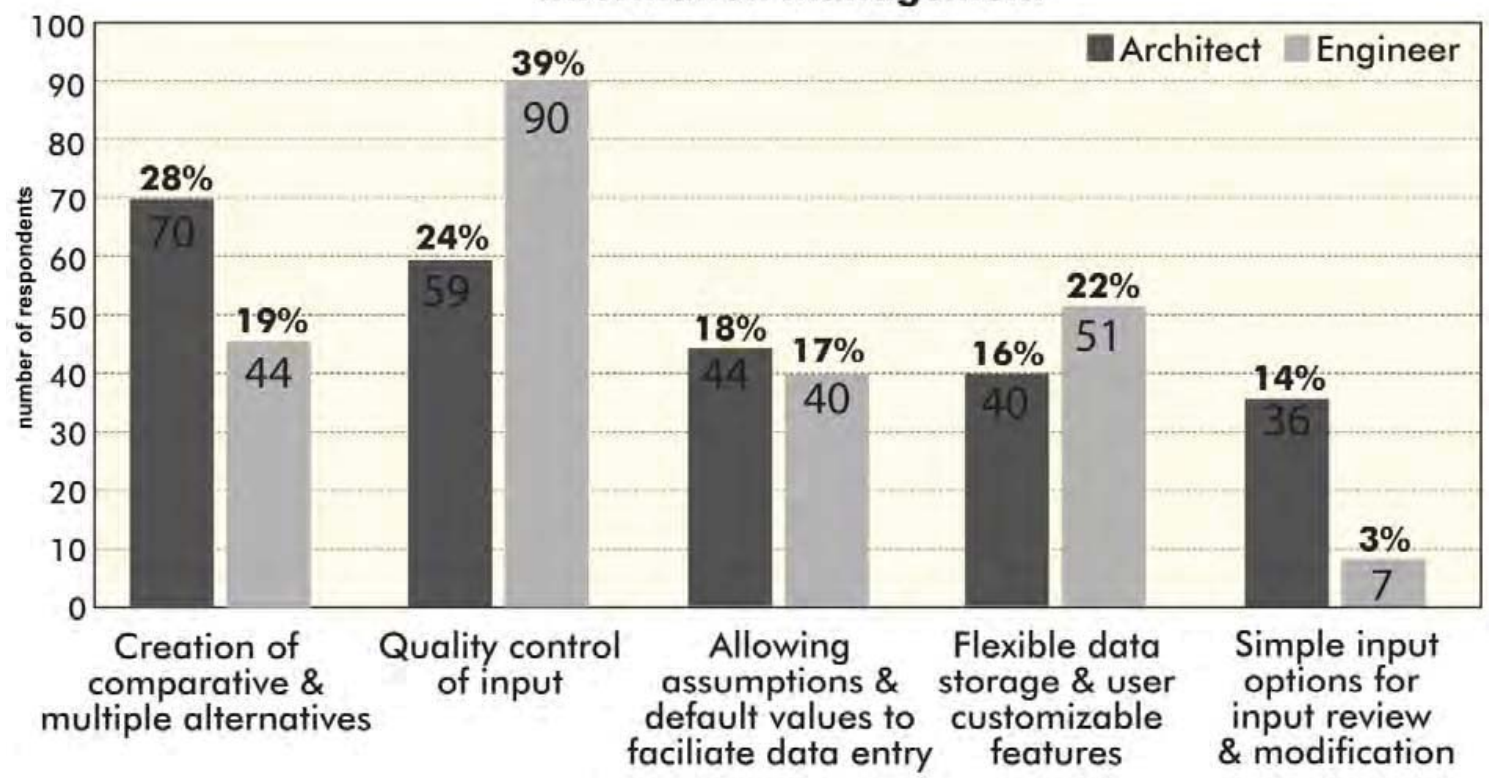

Figure 07: Ranking criteria concerning information management of BPS interfaces

\section{Intelligence of Knowledge Base \& Adaptability to Design Process}

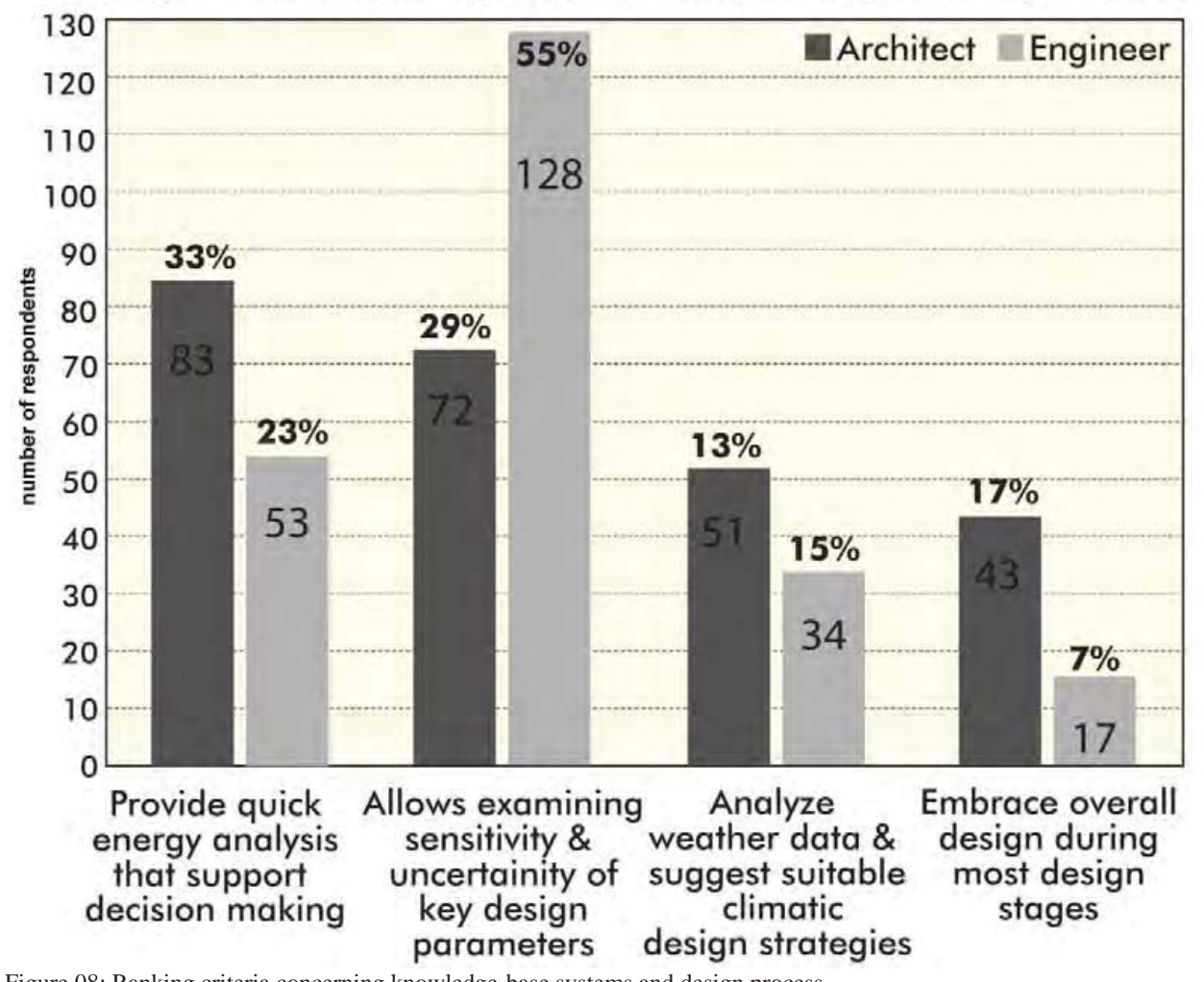

Figure 08: Ranking criteria concerning knowledge-base systems and design process 
Tool Accuracy and Validity

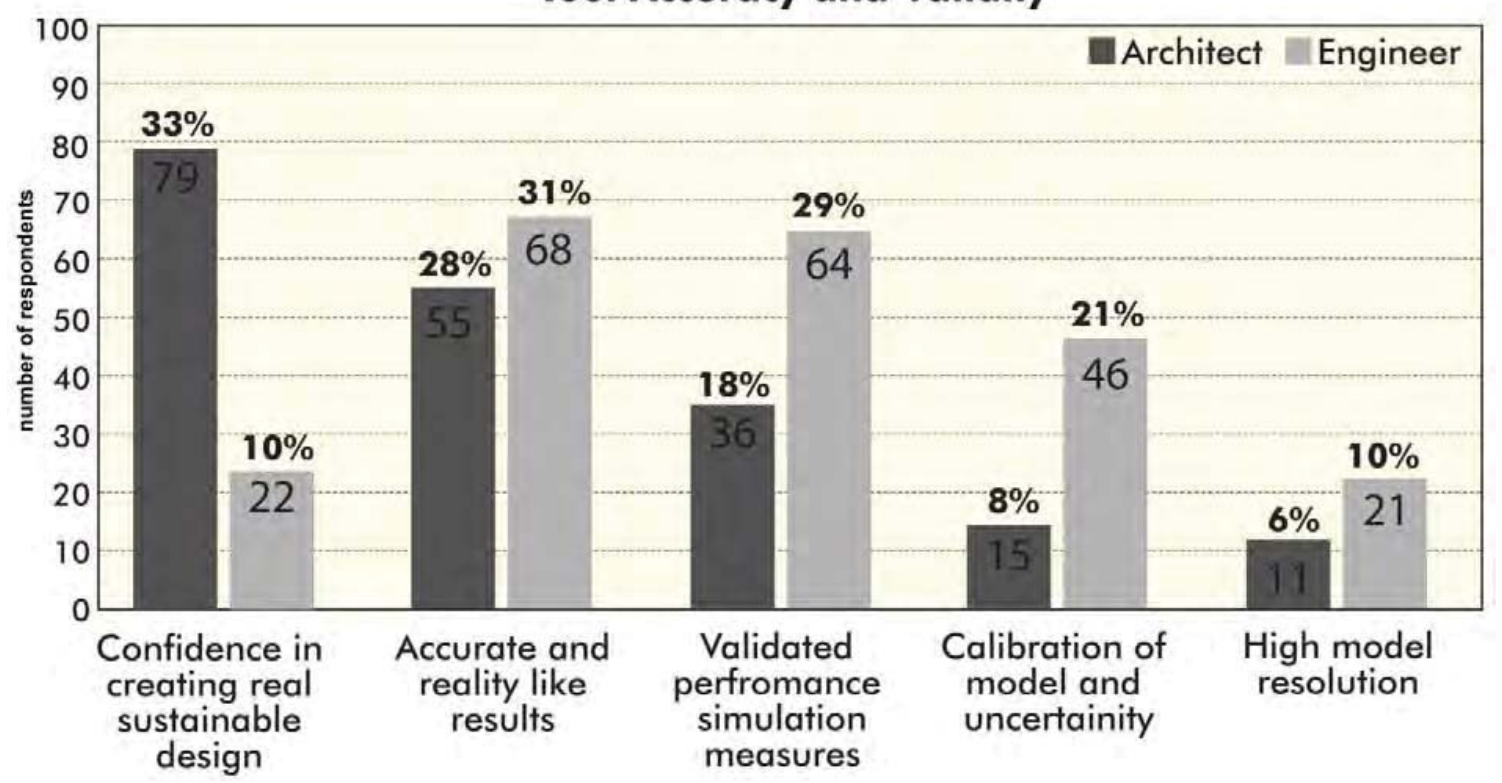

Figure 09: Ranking criteria concerning tools accuracy

\section{Interoperability of Building Model}

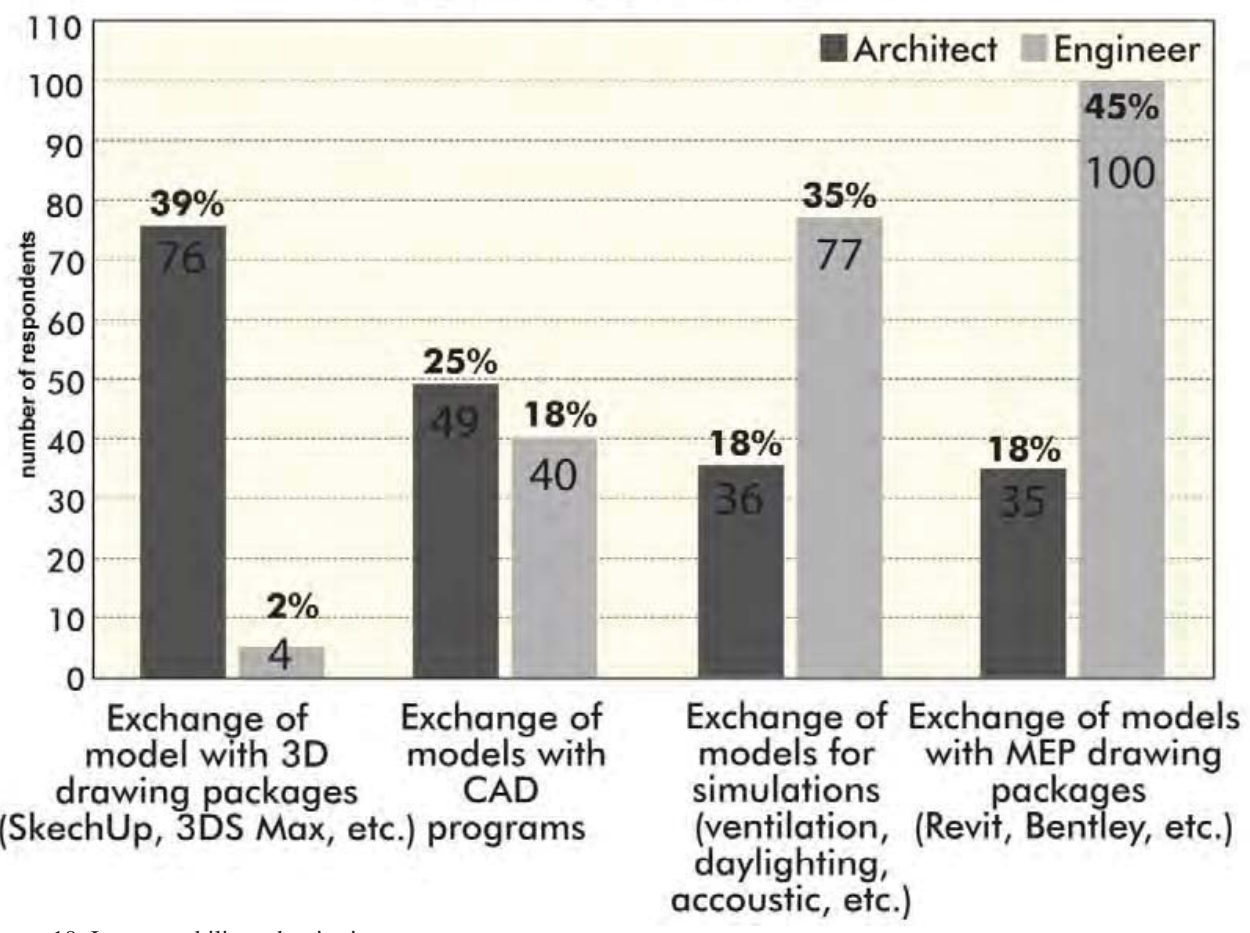

Figure 10: Interoperability sub criteria 
Architects versus Engineers: Priorities for Selecting BPS Tools

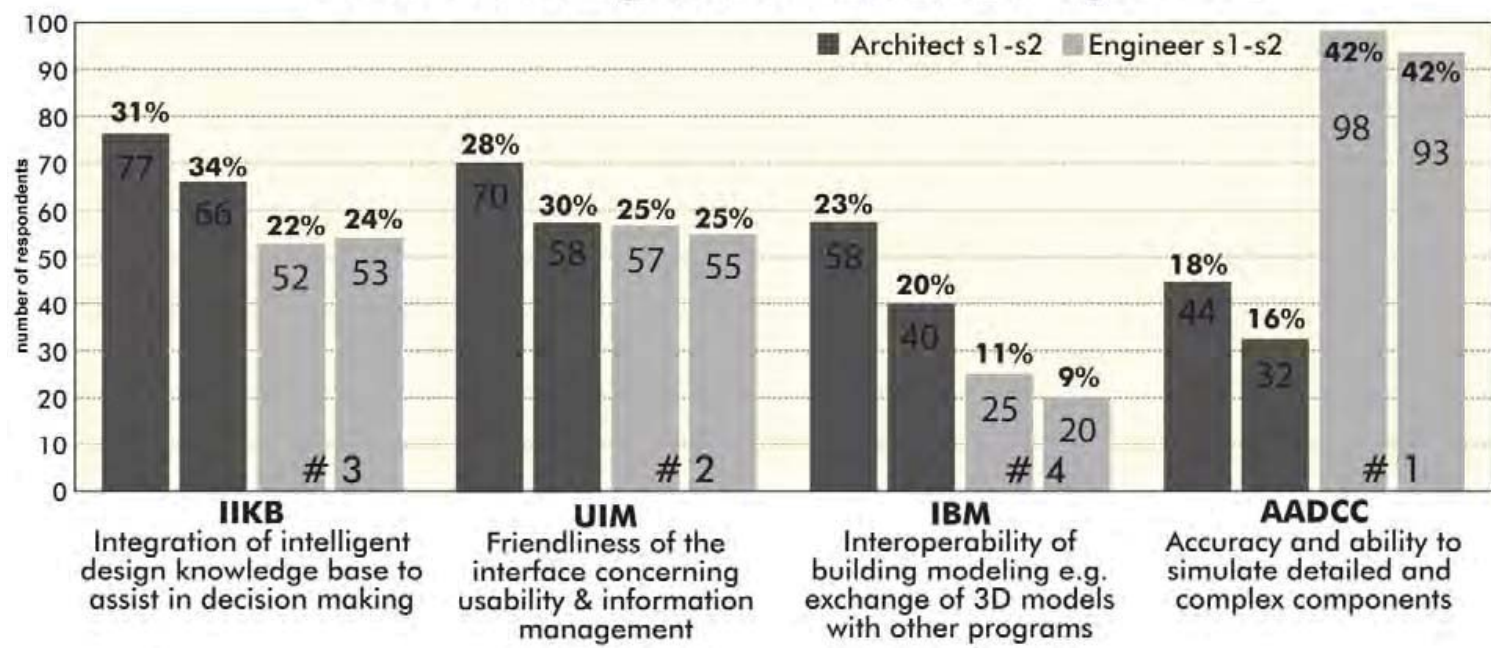

Figure 11: Ranking the most important features of a simulation tool

Architects versus Engineers: Ranking Ten Tools

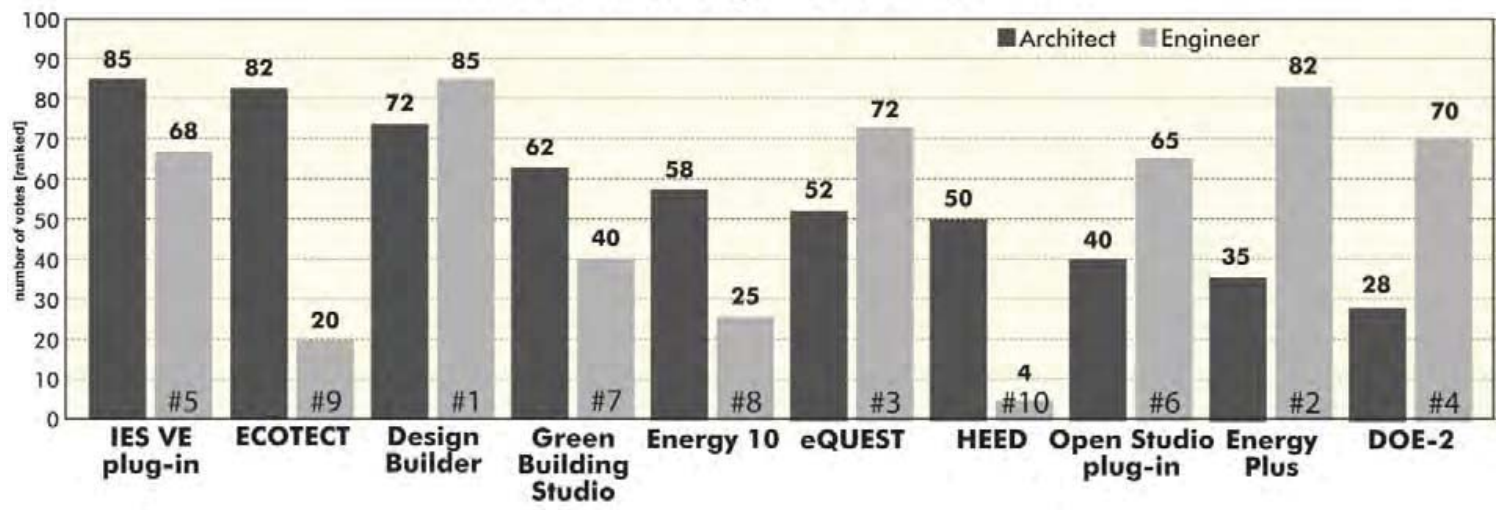

Figure 12: Ranking the ten tools according to architects and engineers

Table 01: Building performance simulation tools selection criteria

\begin{tabular}{|c|c|}
\hline \multirow[b]{2}{*}{ UIM } & Usability and Information Management (UIM) of Interface \\
\hline & $\begin{array}{l}\text { The ‘usability’ incorporates the functional operation of a tool. Keywords: output and input representation, } \\
\text { navigation, control, learnability, documentation, online help, error diagnostics. } \\
\text { The 'information management' is responsible for allowing assumptions, facilitate data entry and control the input quality. } \\
\text { Keywords: input quality control, comparative reports creation, performance benchmarking, data storage, user } \\
\text { customization, input review \& modification }\end{array}$ \\
\hline \multirow[b]{2}{*}{ IIKB } & Integration of Intelligent design Knowledge-Base (IIKB) \\
\hline & $\begin{array}{l}\text { The knowledge-base supports decision making and provides quantitative and qualitative advice regarding the influence } \\
\text { of design decisions. Keywords: pre set building templates \& building components, heuristic/prescriptive rules, } \\
\text { procedural methods, building codes compliance, design guidelines, case studies, design strategies } \\
\text { The intelligence entails finding quantifiable answers to design questions in order to optimise the design. } \\
\text { Keywords: context analysis, design solutions \& strategies optimisation, parametric \& sensitivity analysis, 'what if' } \\
\text { scenarios, compliance verification, life cycle and economical analysis }\end{array}$ \\
\hline \multirow[b]{2}{*}{ AADCC } & Accuracy of tools and Ability to simulate Detailed \& Complex building Components (AADCC) \\
\hline & $\begin{array}{l}\text { The accuracy of tools includes analytical verification, empirical validation and comparative testing of simulation. } \\
\text { Keywords: BESTEST procedure, quality assurance, calibration, post-construction monitoring, error range } \\
\text { The other part of this criterion deals with the ability to simulate complex building components with high model } \\
\text { resolutions Keywords: passive technologies, renewable energy systems, HVAC systems, energy associated } \\
\text { emissions, green roofs, double skin facades, chilled beams, atria, concrete core conditioning etc. }\end{array}$ \\
\hline \multirow[b]{2}{*}{ IBM } & Interoperability of Building Modelling (IBM) \\
\hline & Interoperability corresponds to the ability multidisciplinary storing and sharing of information with one virtual \\
\hline
\end{tabular}


representation. Keywords: gbXML, CAD, IFC, BIM, design phases, design team, model representation

\begin{tabular}{|c|c|}
\hline & representation. Keywords: gbXML, CAD, IFC, BIM, design phases, design team, model representation \\
\hline \multirow{2}{*}{ IBDP } & Integration with Building Design Process (IBDP) \\
\cline { 2 - 2 } & $\begin{array}{c}\text { IBDP corresponds to the integrating of BPS tools during the whole building design delivery process. Keywords: } \\
\text { multidisciplinary interfaces, design process centric, early \& late design stages }\end{array}$ \\
\hline
\end{tabular}

